\title{
FORMAÇÃO DOCENTE E JUSTIFICATIVAS SOBRE O BAIXO APROVEITAMENTO ESCOLAR
}

\author{
FORMACIÓN DOCENTE Y JUSTIFICATIVAS SOBRE EL BAJO \\ APROVECHAMIENTO ESCOLAR
}

\section{TEACHER TRAINING AND JUSTIFICATION ON LOW SCHOOL ACHIEVEMENT}

Ana Maria FALSARELLA ${ }^{1}$

RESUMO: O estudo explora a vinculação entre a formação docente e as justificativas correntes sobre o baixo aproveitamento escolar. Tem por objetivos: a) discutir a ligação entre concepções sobre dificuldades de aprendizagem e formação docente; b) destacar a relevância do estudo e da discussão sobre dificuldades de aprendizagem e seu enfrentamento na formação de professores; c) apontar a importância de que os professores adquiram uma visão mais ampla sobre as repercussões das condições socioeconômicas no aproveitamento escolar dos alunos. A partir de dificuldades observadas entre professores em distinguir problemas pontuais e transitórios de aprendizagem, o texto mostra como a circulação de culpas (da criança, da família, do grupo social, dos professores ou da escola) impede uma discussão mais abrangente sobre as condições socioeconômicas que engendram o fracasso e a decorrente exclusão escolar, tanto a explícita (abandono e evasão) quanto à implícita (acesso e frequência sem aprendizagem).

PALAVRAS-CHAVE: Formação docente. Problemas de aprendizagem. Fracasso escolar. Exclusão escolar.

RESUMEN: El estudio explora la vinculación entre la formación docente y las justificaciones corrientes sobre el bajo aprovechamiento escolar. Tiene por objetivos: a) discutir el vínculo entre concepciones sobre dificultades de aprendizaje y formación docente; b) destacar la relevancia del estudio y de la discusión sobre dificultades de aprendizaje y su enfrentamiento en la formación de profesores; c) señalar la importancia de que los profesores adquieran una visión más amplia sobre las repercusiones de las condiciones socioeconómicas en el aprovechamiento escolar de los alumnos. A partir de dificultades observadas entre profesores en distinguir problemas puntuales y transitorios de aprendizaje, el texto muestra cómo la circulación de culpas (del niño, de la familia, del grupo Social, de los profesores o de la escuela) impide una discusión más amplia sobre las condiciones socioeconómicas que engendran el fracaso y la consiguiente exclusión escolar, tanto la explícita (abandono y evasión) como la implícita (acceso y frecuencia sin aprendizaje).

${ }^{1}$ Universidade de Araraquara (Uniara), Araraquara - São Paulo - Brasil. Docente do Programa de PósGraduação em Processos de Ensino, Gestão e Inovação. E-mail: anafalsarella@ gmail.com. 
PALABRAS-CLAVE: Formación docente. Problemas de aprendizaje. Fracaso escolar. Exclusión escolar.

ABSTRACT: The study explores the link between teacher education and current justifications for low achievement. Its objectives are: a) to discuss the connection between conceptions about learning difficulties and teacher training; $b$ ) highlight the relevance of the study and the discussion about learning difficulties and their confrontation in teacher training; c) To point out the importance of teachers gaining a broader view of the repercussions of socioeconomic conditions on students' achievement in school. Based on the difficulties observed by teachers in distinguishing specific and transient learning problems, the text shows) how the circulation of faults (of the child, the family, the social group, the teacher or the school) precludes a more comprehensive discussion on the socioeconomic conditions that engender failure and the resulting school exclusion, both explicit (abandonment and avoidance) and implicit (access and attendance without learning).

KEYWORDS: Teacher Education. Learning problems. School failure. School exclusion.

\section{Introdução}

O objeto de estudo deste ensaio são as justificativas comuns dadas por docentes para o baixo aproveitamento escolar de crianças oriundas das classes populares. Buscamos associá-las à formação docente, ou melhor, à ausência de formação nesse aspecto.

Contribuir para clarear essa vinculação é um dos objetivos. Outro é destacar a importância de que a formação dos professores, inicial e continuada, contemple um estudo mais aprofundado das dificuldades que podem interferir na aprendizagem dos alunos. O último é apontar a importância de que os professores adquiram uma visão mais ampla sobre as condições socioeconômicas das famílias e como elas podem afetar os julgamentos feitos pela escola a respeito dos alunos. Não se espera que os docentes desenvolvam a competência de estabelecer diagnósticos, o que concerne a profissionais da área da saúde, mas justamente que sejam capacitados para distinguir os problemas que tenham solução por meio de sua própria atuação didáticopedagógica, diferenciando-os de outros que demandam atendimento paralelo de profissionais especializados, integrado às intervenções docentes. Tratamos em especial da (não) aprendizagem de crianças pobres, as maiores vítimas do não-acesso ao saber escolar, mesmo que frequentem escolas.

Caracterizamos este artigo como estudo exploratório, pois: a) busca 
proporcionar uma visão geral sobre o objeto de estudo; b) tem por base observações da prática cotidiana da autora; c) apresenta, avalia e analisa padrões e ideias préexistentes e recorrentes sobre a temática proposta; d) envolve levantamento bibliográfico que visa estimular a reflexão sobre o assunto.

Haja vista a relação direta entre a não-aprendizagem e o binômio inclusãoexclusão escolar e social, verificamos a impossibilidade de tratar de forma desvinculada os temas dificuldades de aprendizagem dos alunos e formação de profissionais da educação, como também de estudá-los sem considerar o contexto socioeconômico e político que permeia a atuação desses profissionais, seja relativo às condições de trabalho, seja relativo às condições de vida da população usuária da escola.

O presente estudo foi desencadeado por inquietações que têm nos afligido no transcorrer de nossa experiência como professora de ensino básico, como membro de equipes gestoras de escolas públicas e particulares, como docente em cursos superiores de formação de educadores (graduação/licenciatura em Pedagogia e Letras, complementação pedagógica para licenciados, pós-graduação lato sensu, formação continuada para professores e gestores), como orientadora na elaboração trabalhos de conclusão de cursos, de projetos educacionais e de dissertações de mestrado, além da participação em bancas de defesa de trabalhos acadêmicos.

Além de nossa experiência pessoal, o permanente contato com professores e gestores que atuam no ensino básico possibilitou-nos testemunhar a angústia desses profissionais ao se sentirem incompetentes no trato com alunos com dificuldades em aprender o conhecimento convencional escolar.

Debates ocorridos no desenvolvimento de aulas/cursos e conversas informais com esses mesmos profissionais da educação - colegas de trabalho ou alunos - nos alertaram para a questão da indefinição e, ao mesmo tempo, para a banalização de termos relacionados à não- aprendizagem, tais como problemas, dificuldades, déficits e distúrbios, dos quais os alunos seriam portadores.

\section{Jargões da educação}


Diríamos que tais termos são como palavras mágicas, slogans, jargões utilizados tão exaustivamente no vocabulário educacional contemporâneo, que, no final, ninguém sabe exatamente o que significam.

Ao tratar da autonomia dos professores, Contreras (2002) denuncia o caráter de artifício ideológico de tais slogans, cujos significados se obscurecem pelo uso frequente: citar palavras ou expressões sem defini-las com exatidão pressiona por consensos sem entendimentos mais aprofundados. Conforme o autor:

A autonomia dos professores, bem como a própria ideia de seu profissionalismo, são temas recorrentes nos últimos tempos nos discursos pedagógicos. No entanto, sua profusão está-se dando sobretudo na forma de slogans, que como tal se desgastam e seus significados se esvaziam com o uso frequente. Pode-se dizer que, por serem slogans, são utilizados em excesso para provocar uma atração emocional, sem esclarecer nunca o significado que se lhes quer atribuir. Funcionam assim como palavras com aura, que evocam ideias que parecem positivas e ao redor das quais se pretende criar consenso e identificação. Porém, é provável que parte do êxito dos slogans em geral, com o da autonomia dos professores em particular, resida em que na verdade escondem diferentes pretensões e significados, em que diferentes pessoas estejam entendendo ou querendo dizer coisas diversas com as mesmas palavras, embora aparentemente todos digam o mesmo. (CONTRERAS, 2002, p. 23)

No nosso entender, a questão das dificuldades de aprendizagem tem o mesmo caráter de jargão ou palavra com aura.

\section{O problema é o aluno e sua família}

Com relação a essas dificuldades, percebemos que, via de regra, elas são concentradas no aluno, é ele o problema. Raramente os membros de uma equipe escolar questionam e refletem sobre seus próprios procedimentos, sobre a estrutura escolar e as circunstâncias sistêmicas em que atuam e sobre as condições de vida da população, fatores que delimitam seu trabalho.

Causa-nos espanto também a facilidade com que, por meio de diagnósticos infundados, principalmente no início da escolarização, alunos são marcados com estigmas de hiperativos ou disléxicos, dentre outros termos, isto é, por rótulos que colam feito tatuagem e os acompanham por todo o tempo em que permanecem na escola, isso quando não os levam a abandoná-la. 
De fato, investigação levada a efeito por Aparecido (2000) constatou como a disseminação entre os educadores de um tipo de literatura relacionada a nãoaprendizagem, marcada por expressões como Transtorno do Déficit de Atenção e Hiperatividade (TDAH) e Disfunção Cerebral Mínima (DCM). Portanto, com enfoque patologizante centrada em características pessoais dos alunos, foi incorporada e divulgada pelos sistemas escolares a partir dos anos de 1970 no Brasil, alcançou a esfera da escola e, até hoje, contribui para justificar qualquer tipo de baixo rendimento escolar.

A mesma autora verificou a utilização de diferentes termos por diferentes autores para se referir a grupos de crianças com características muito semelhantes: oriundas de famílias pobres, em especial as que estão em processo de alfabetização. Assim, a extrema amplitude das concepções disseminadas, que são de difícil mensuração objetiva, mais serviu para confundir o professorado do que para esclarecêlo, levando o profissional a entender que qualquer dificuldade que ocorra nos processos de ensino pode ser interpretada como problema de aprendizagem, como um distúrbio pessoal do aluno e, como tal, fora do alcance da intervenção docente.

Abrindo um parêntese com relação aos anos iniciais da escolarização, podemos destacar que, após a divulgação dos estudos de Emília Ferreiro ${ }^{2}$, na década de 1980, outras palavras passaram a fazer parte do vocabulário dos profissionais da educação, principalmente daqueles voltados à alfabetização.

Segundo Emília Ferreiro, durante a alfabetização, a criança passa por uma série de passos ordenados para compreender a natureza do sistema alfabético, sendo que cada passo é caracterizado por esquemas conceituais específicos. Para chegar ao nível de aprendizado desejável para ser considerada usuária competente da leitura e da escrita, a criança percorre as seguintes etapas: pré-silábica, silábica, silábica-alfabética, alfabética e alfabética-ortográfica ${ }^{3}$. Pois bem, as palavras que identificam cada etapa também se tornaram slogans. Não se prestam a uma melhor compreensão do processo de letramento e ao planejamento de intervenções mais adequadas, mas a uma estigmatização mais sofisticada dos alfabetizandos.

Como nossa experiência abarca tanto escolas públicas quanto escolas privadas, foi-nos possível constatar ainda que na escola privada há, via de regra, todo um conjunto de profissionais para corroborar ou não tais diagnósticos e para dar suporte

${ }^{2}$ Várias obras, das quais podemos destacar Alfabetização em processo e Reflexões sobre alfabetização. ${ }^{3}$ Não entramos em detalhes sobre as etapas de aquisição da leitura e escrita, pois não fazem parte de nosso objeto de estudo. No entanto, há vasta literatura pedagógica, impressa e online disponível sobre o assunto. 
aos alunos que, porventura, tropecem em um ou outro aspecto da aprendizagem escolar. O mesmo não acontece na escola pública, onde os alunos que apresentam dificuldades são, salvo raras exceções, abandonados à própria sorte, seja por falha da escola em organizar-se para dar-lhes suporte e evitar que dificuldades transitórias se transformem em déficits permanentes, seja pela omissão do Estado que não provê as escolas de condições para garantir uma educação escolar digna às crianças e adolescentes das famílias de baixa renda que vivem nas amplas periferias das cidades brasileiras.

Reconhecer que o número de crianças com problemas físicos ou psíquicos que dificultam sua aprendizagem é, via de regra, menor do que o apontado pelas escolas e que uma criança que não consegue aprender em uma escola de má qualidade não é necessariamente ela a problemática, "não significa fazer o elogio da pobreza", afirma Patto (1997, p.288). Certamente, "há uma parcela que precisaria de um bom atendimento especializado fora da escola, como tantas crianças mais ricas que recebem apoio médico, psicológico, fonoaudiológico, quando necessitam" (id.ibid.). Fechar os olhos a isso é mascarar o problema, omitir-se, desobrigar-se diante dos que fracassam na aprendizagem escolar.

Ignorar que uma parte das crianças necessita de ajuda extraescolar para superar dificuldades é uma forma cruel de discriminação, pois são essas mesmas crianças que passam a constituir os excluídos do interior, condenados à eliminação branda, nos termos de Bordieu (2002), quer dizer, têm acesso à escola, nela permanecem, mas sem o domínio dos fundamentos escolares básicos.

\section{Retrospectiva}

Embora as explicações para o fracasso escolar remontem à virada do século XIX, a questão é mais exaustivamente debatida a partir dos anos 1970 e 1980. De acordo com Patto (1997), no início do século XX, a não-aprendizagem das crianças pobres recebia explicações de cunho racista e higienista. Os pobres, em sua maioria negra, teriam deficiências físicas e psíquicas inatas à sua origem e ao seu ambiente. Entre as décadas de 1930 a 1960 têm lugar explicações de caráter biopsicológico, quer dizer, problemas físicos, neurológicos e emocionais seriam os impeditivos da aprendizagem. 
Nos anos de 1970 essas explicações são substituídas. Ao lado da justificativa de possíveis quadros patológicos apresentados pelos alunos, surge a teoria da carência cultural: as famílias de baixa renda não teriam capital cultural para transmitir aos filhos e, por isso, eles iriam mal na escola. Posteriormente, esta é transformada em teoria da diferença cultural, entendendo-se que o ambiente familiar e comunitário das crianças oriundas de minorias apresentaria diferenças marcantes com relação às competências exigidas pela escola, o que impediria sua adaptação ao ambiente escolar. Em comum a todas essas propostas explicativas está o fato de situarem a culpa pelas dificuldades escolares ou nos próprios alunos ou em suas famílias, dando origem a estereótipos e preconceitos em torno de pobres não-brancos (PATTO, 1997) e deixando de lado considerações de ordens socioeconômicas e ideológicas que marcam a hierarquia de classes na sociedade capitalista. Até então, o fracasso na escola era atribuído a distúrbios pessoais dos alunos ou à precária situação socioeconômica e cultural de suas famílias, que seriam responsáveis por sua própria condição.

\section{A culpa é dos professores e da escola}

Nos anos 1980 e 1990, crianças pobres continuam não aprendendo nas escolas públicas e a culpa passa a ser atribuída às próprias escolas. Gestores e professores com formação deficiente estariam falhando. Aos gestores faltariam o empreendedorismo e a capacidade de liderança que têm os que trabalham nas eficientes escolas particulares, além de não fazerem o monitoramento - entendido como controle e cobrança - do trabalho dos professores. Aos professores, por sua vez, faltariam técnicas didáticopedagógicas para trabalhar com todos os alunos e, ao mesmo tempo, atender a cada qual em suas particularidades. Acresce-se a isso que as equipes escolares, por variados motivos, teriam dificuldade em construir coletivamente um projeto pedagógico adequado às suas realidades e em desenvolver um trabalho coletivo calcado nesse projeto.

Ora, responsabilizar os profissionais do magistério pelas mazelas da escola pública é basicamente injusto, pois eles próprios "são produtos de uma formação insuficiente, porta-vozes da visão de mundo da classe hegemônica e vítimas da desvalorização profissional e de uma política educacional burocrática, tecnicista e de fachada" (PATTO, 1997, p.289). Por outro lado, colocá-los em um mesmo patamar é 
grave equívoco, uma vez que os profissionais do magistério não formam um grupo homogêneo e falar deles genericamente não nos dá a medida de suas dificuldades e aflições pessoais cotidianas.

A extensão legal do acesso ao ensino fundamental a toda a população e críticas surgidas à atribuição da culpa pela não escolarização à própria população levaram a reformulações no pensamento pedagógico. É assim que as reformas educativas dos anos de 1990 trouxeram novas propostas para evitar o fracasso e o abandono da escola pelos alunos. A política educacional desencadeada pela Lei de Diretrizes e Bases da Educação Nacional (LDB, n. 9394/96) possibilitou a adoção de ciclos de aprendizagem com progressão continuada, o que, na prática, impede a reprovação. No entanto, muitas crianças pobres das pobres escolas públicas parecem que insistem em não aprender, assim como persistem as dificuldades do professor em ensiná-las. Ao lado de uma estratégia de responsabilização do professor, o Estado assume uma posição de isenção, de alheamento, como se as dificuldades dos alunos não existissem a não ser no imaginário dos mal formados e incompetentes professores que deixam que os alunos cheguem até mesmo ao ensino médio sem que dominem conhecimentos e habilidades básicas.

Chauí (2004) analisa essa situação por meio da crítica à doutrina neoliberal que, segundo a autora, legitima a proposta de modernização do Estado transformando-o em estado mínimo: há um enxugamento do papel do Estado na garantia dos direitos sociais, dentre eles o direito à boa educação pública e gratuita, ou seja, o Estado se coloca mais a serviço do capital do que a serviço do cidadão. Os discursos oficiais defendem o direito universal à educação escolar. As ações do Estado, no entanto, denunciam o investimento insuficiente no ensino público, com a crescente proletarização da profissão docente e a continuidade de uma estrutura escolar sufocante e burocratizada. Culpar os professores pelo fracasso da escola em ensinar desobriga o Estado de cuidar de sua formação, de garantir adequadas condições de trabalho e de oferecer atendimento especializado às crianças que dele necessitam.

Bourdieu (2002) explica esse paradoxo da democratização - a descoberta de que a escola libertadora mantém funções conservadoras - da seguinte forma: a partir dos anos de 1950, uma das transformações que mais afetaram os sistemas de ensino foi a entrada em cena de categorias sociais antes excluídas da escola. Com a massificação, há uma transformação do discurso pedagógico sobre a escola, que passa a difundir a ideia de que o fracasso escolar não é mais imputável às deficiências pessoais ou naturais dos 
alunos: "as causas de aparência natural, como o dom ou o gosto, cedem lugar a fatores sociais mal definidos, como a insuficiência dos meios utilizados pela Escola, ou a incapacidade e a incompetência dos professores" (BOURDIEU, 2002, p.220).

Para o autor, os que fracassam são votados a uma exclusão mais estigmatizante, pois aparentemente tiveram sua oportunidade e não a aproveitaram, e mais total, pois os postos no mercado de trabalho são reservados e de fato ocupados pelos mais escolarizados. Surgem, então, "práticas de exclusão brandas ou insensíveis" (BOURDIEU, 2002, p.222), porque contínuas, graduais e imperceptíveis, que passam despercebidas tanto pelas vítimas quanto pelos que a exercem. A eliminação branda, ao se desdobrar no tempo, provoca nos que a vivenciam a dissimulação da verdade, o que pode perpetuar-se para além da escola.

Assim, com a chegada da nova clientela ao sistema escolar, surgem novas figuras, às quais Bourdieu (2002) chama de excluídos do interior, referindo-se àqueles que têm acesso à escola, nela permanecem por longos anos e saem sem aprender os conteúdos básicos para sobreviver na sociedade, pois a estrutura de distribuição diferencial dos benefícios escolares e dos correlatos benefícios sociais foi mantida na essência, embora com uma diferença fundamental: "o processo de eliminação foi diferido e estendido no tempo e, por conseguinte, como que diluído na duração; a instituição é habitada, permanentemente, por excluídos potenciais que introduzem nela as contradições e os conflitos associados a uma escolaridade cujo único objetivo é ela mesma”. (BOURDIEU, 2002, p.221). A definição da identidade social feita pela instituição escolar explica porque o fracasso escolar é visto como catástrofe até nos meios populares, que sabem que sem escolarização, as oportunidades fora da escola são muito limitadas. Ao mesmo tempo, os alunos não percebem o sentido da escolarização e como os conhecimentos tratados na escola gerarão oportunidades fora dela.

\section{Considerações finais}

Tratamos nesse artigo da dificuldade na detecção e de problemas relacionados à aprendizagem e na diferenciação entre os que demandam ações pedagógicas por parte da escola e os que demandam apoio de profissionais especializados. Defendemos uma formação docente mais criteriosa e fundamentada nesse sentido. 
As dificuldades de aprendizagem a que nos referimos situam-se em diferentes áreas afetas ao desempenho escolar, dentre as quais se destacam a comunicação verbal, o domínio da leitura e da escrita e o raciocínio matemático. Reconhecemos a ocorrência dessas dificuldades quando o desempenho dos aprendizes se apresenta substancialmente abaixo do esperado, considerados a idade e o grau de escolaridade.

Registramos o considerável papel que tem o professor na detecção precoce desses problemas. É na escola que as primeiras exigências de desempenho acadêmico bem sucedido se colocam. Reconhecer o problema, pesquisar os possíveis fatores que o determinam e encaminhar soluções é o caminho para impedir que crianças cresçam estigmatizadas por rótulos como lentas, desatentas, desmotivadas e ineptas.

Vistas como frutos de famílias desorganizadas, desinteressadas e desestruturadas pelas equipes escolares e como frutos da incompetência dessas equipes pelos técnicos do sistema educacional, falta um olhar individualizado sobre cada criança em sua aprendizagem e, ao mesmo tempo, mais amplo sobre as condições socioeconômicas que engendram o insucesso na escola. Há que se superar explicações simplistas e fatalistas, que impõem à família ou à classe social, por um lado, e à escola ou aos professores por outro, toda a responsabilidade por um fracasso escolar que não escolheram.

Entendemos que investir na formação dos profissionais da educação para a detecção de sinais significativos e seguros de problemas de aprendizagem pode facilitar a superação e o enfrentamento de equívocos e mitos, tais como toda criança de família desestruturada tem dificuldades, a família não ensina disciplina e respeito, os pais não impõem limites aos filhos ou os pais não valorizam a escola. Por outro lado, buscar encaminhamentos corretos para o enfrentamento e solução desses problemas significa também exigir do Estado a efetiva melhoria das condições não só educacionais, mas também de bem estar social, em geral ausentes nas localidades mais pobres, o que é perceptível pela falta de recursos no apoio à saúde física e mental da população com limitadas condições econômicas.

Apontamos que, por muito tempo, as dificuldades de aprendizagem de crianças pobres foram atribuídas às suas próprias deficiências físicas ou mentais, à constituição de suas famílias e ao seu meio econômico-social e que, posteriormente, estudos na área da educação passaram a apontar a incompetência e o preconceito que grassam nas escolas como culpados pelo fracasso escolar.

Assinalamos que, se não podemos aceitar fatores familiares e sociais como justificativa para que um professor desista da aprendizagem do aluno, não podemos 
admitir também que ao professor seja atribuída a responsabilidade por sua própria formação deficiente. Mesmo reconhecendo que o fracasso escolar em massa de crianças oriundas das classes populares não é justificável, é óbvio que uma parte delas - como, aliás, acontece nos estratos sociais mais favorecidos - carece de ajuda especializada para superar dificuldades.

Concluímos que a maior vítima dessa circulação de culpas é o próprio aluno, que deveria ser sujeito ativo no processo de aprendizagem. Ele não é olhado como pessoa em formação, passível de apresentar dificuldades passageiras em seu percurso escolar, mas considerado um problema permanente e sem solução.

Para encerrar, trazemos um trecho de texto de alerta escrito por Cecília Meireles em 1932, aos que se conformam com respostas prontas e fáceis, não se incomodando com a busca de soluções mais aprimoradas.

Os rotineiros pacíficos, viciados na imobilidade das ideias, e os rotineiros pretensiosos, impregnados da convicção de uma sabedoria insuperável, constituem duas fileiras imensas, entre as quais passam a custo, e com uma impressionante coragem, os que se acostumaram a pôr sobre todas as coisas uma claridade sem enganos, e conquistaram o gosto de atingir cada dia um ponto mais alto para o seu destino. (MEIRELES, 1932).

\section{REFERÊNCIAS}

APARECIDO, A. M. B. Os distúrbios de aprendizagem como categoria explicativa para o baixo rendimento escolar: revisão da literatura especializada publicada nas décadas de 60, 70 e 80. Dissertação (Mestrado em Educação), Pontifícia Universidade Católica de São Paulo (PUC-SP), 2000.

BOURDIEU, P. Escritos de educação. Petrópolis: Vozes, 2002.

CHAUI, M. Convite à filosofia. São Paulo: Ática, 2004.

CONTRERAS, J. A autonomia dos professores. São Paulo: Cortez, 2002.

FERREIRO, E. Alfabetização em processo. São Paulo: Cortez-Autores Associados, 1980.

FERREIRO, E. Reflexões sobre alfabetização. São Paulo: Cortez, 2001.

MEIRELES, C. Aprender. Diário de Notícias: Rio de Janeiro, 10.dez.1932. Extraído da Revista Educação, ano 28, n. 245, set.2001. 
PATTO, M. H. S. Introdução à psicologia escolar. São Paulo: Casa do Psicólogo, 1997.

\section{Como referenciar este artigo}

FALSARELLA, Ana Maria. Formação docente e justificativas sobre o baixo aproveitamento escolar. Temas em Educ. e Saúde, Araraquara, v.13, n.1, p. 2-13, jan./jun. 2017. DOI <https://doi.org/10.26673/rtes.v13.n1.jan-jun2017.9818>. ISSN: $1517-7947$.

Submetido em: 09/05/2017

Aprovado em: 20/08/2017 